\section{B A Institute of \\ YK Business Administration \\ 六下 \\ Karachi \\ Leadership and Ideas for Tomorrow}

Business Review

Volume 14 Issue 1 January-June 2019

$1-1-2019$

\title{
Emotional intensity: an additional dimension to understand emotional confidence and purchase intentions
}

Wajid Hussain Rizvi

Institute of Business Administration, Karachi, Pakistan

Follow this and additional works at: https://ir.iba.edu.pk/businessreview

Part of the Finance Commons, Management Sciences and Quantitative Methods Commons, and the Marketing Commons

\section{(c) (1)}

This work is licensed under a Creative Commons Attribution 4.0 International License.

\section{Recommended Citation}

Rizvi, W. H. (2019). Emotional intensity: an additional dimension to understand emotional confidence and purchase intentions. Business Review, 14(1), 68-80. Retrieved from https://doi.org/10.54784/ 1990-6587.1025

This article is brought to you by iRepository for open access under the Creative Commons Attribution 4.0 License and is available at https://ir.iba.edu.pk/businessreview/vol14/iss1/5. For more information, please contact irepository@iba.edu.pk. 


\title{
Emotional intensity: An additional dimension to understand emotional confidence and purchase intentions
}

\author{
Wajid Hussain Rizvi
}

\begin{abstract}
This paper explores the role of emotional intensity as a determinant of emotional confidence and purchase intentions. It analyzes the difference between low and high emotional confidence and emotional intensity groups in terms of their purchase intentions in the car buying context. Only valence and combined valence-intensity structural models were used to assess respective influences on emotional confidence. The results reveal that the combined impact of valence and intensity has a greater positive and significant influence on emotional confidence. Furthermore, groups with higher emotional confidence and higher emotional intensity show higher purchase intentions. This study contributes to a better understanding of buying behaviour in the car buying context by unveiling the role of emotional intensity on emotional confidence.
\end{abstract}

Keywords Emotional confidence · Emotional intensity · Purchase intentions.

\section{Introduction}

Consumer confidence as a subject area of behavioural sciences has gained rapid attention of academics and practitioners over the last few decades. There is evidence to suggest that consumer confidence is an important indicator of economic health. Despite its importance and popularity, confidence is an overused construct and is not clearly understood.

Confidence is generally conceptualized as a cognitive construct and the way it is measured (i.e. certainty about abilities, beliefs and attitudes) is metacognitive in nature (i.e. cognition about cognition). Alternative conceptualizations are being put forward regarding whether confidence is cognitive or emotion based.

The predominant nature of confidence as a cognitive construct limits its scope and conceptual domain (Kidwell et al 2008; Rizvi and Oney 2018). Very

\footnotetext{
Wajid Hussain Rizvi

Institute of Business Administration, University Road, Karachi-Pakistan

E-mail: wrizvi@iba.edu.pk
} 
little research has been conducted in this area, especially in the context of buying behaviour. Furthermore, none of the papers have addressed emotional intensity as additional dimension in the formation of emotional confidence and specifying variations in purchase intentions across low and high emotional confidence and emotional intensity groups.

Emotional confidence is defined as affective certainty as a consequence of strong positive emotions (Rizvi and Oney 2018). To decipher the formation of emotional confidence it is important to focus on both valence and intensity. Up till now research on the influence of emotions on confidence has been limited to its valence (direction of emotion). No study has tried to demonstrate how the intensity of an emotion in addition to its valence influences emotional confidence. However, in the context of the autobiographical memory experience, evidence suggests that intensity can account for higher variance (Talarico et al 2004).

This paper argues that both valence (direction of an emotion) and intensity (strength) of an emotion influence emotional confidence. The intensity of an emotion determines the overall emotional experience, therefore it is used as an additional dimension to measure the formation of emotional confidence. Six different emotions (happy, pleased, content, excited, satisfied and thrilled) were used for this study in the context of car buying. The empirical evidence sought in this paper using structural equation modelling suggests that emotional response (positive valence) influences emotional confidence (i.e. affective state of certainty).

The results also reveal that the use of emotional intensity (as additional dimension) of each emotion (and overall emotional intensity) increases variance explained in emotional confidence therefore it can be used an additional dimension, along with the valence of an emotion. The classification of the respondents in terms of low and high emotional confidence and emotional intensity shows that there is statistically significant difference between low and high emotional confidence groups in terms of their purchase intentions. Similarly, there is statistically significant difference between low and high emotional intensity groups in term of their purchase intentions. In both observations higher emotional confidence and higher emotional intensity were associated with higher purchase intentions.

This paper contributes to the body of academic literature by making three contributions (a) using emotional confidence as a separate construct in the context of buying behaviour (b) using emotional intensity as an additional dimension to assess its influence on emotional confidence (c) isolation of respondents in terms of emotional confidence and emotional intensity with respect to their purchase intentions in the context of car buying.

\section{Background}

Confidence as a construct has received widespread attention (Bandura 1977; Dominitz and Manski 2004; Gross et al 2009; Stajkovic 2006). The importance of confidence in consumer behaviour is highly recognized (Smith and Swin-

Business Review: (2019) 14(1):68-80 
yard 1988; Berger and Mitchell 1989). In addition to other economic indicators consumer confidence is considered as an important indicator to predict future economic activity (Curtin 1982; Dees and Brinca 2013; Ludvigson 2004). There is evidence to suggest that confidence influences purchase intentions directly (Howard and Sheth 1969; Laroche et al 1996). People with higher confidence reflect higher intentions to buy rather than just attitudinal responses (Ajzen 2005; Petty et al 2002).

The concept of confidence was pioneered by Howard and Sheth (1969). He argued that confidence should not be restricted to a dimension of attitude strength rather it should be conceptualized as a separate construct and there is need to layout its theoretical framework in order to assess its influence on buying behavior. Lack of progress in developing a theoretical framework of confidence can be linked to its conflicting explanations.

On one hand, confidence is conceptualized as a feeling based construct (Compte and Postlewaite 2004) and on the other hand it is conceptualized as a cognitive construct (Smith and Swinyard 1988). Likewise, formation of confidence is associated with diverse antecedents that includes both beliefs and emotions. Smith and Swinyard (1988) argues that "confidence (or certainty) is a cognitive construct that reflects one's conviction in one's belief" and antecedents of confidence are quantity of information, credibility of information and consistency of information. Gross et al (2009) states that positive emotions such as pride and hope influence confidence.

Predominantly, confidence is conceived as a cognitive construct (Bearden et al 2001; Berger 1992; Kahneman and Lovallo 1993; Krosnick et al 1993; Petty et al 2002; Siegrist et al 2005; Stajkovic 2006; Sniezek et al 1990). Alternative explanations are beginning to emerge such as conceptualization of emotional confidence. Academic literature on emotional confidence is sparse; addressing only the nature of emotional confidence in the area of emotional calibration. Specifically, Kidwell et al (2008) has postulated that consumers who are emotionally calibrated not only possess high levels of emotional ability but are also confident in their feelings of self-assurance and conviction.

Despite coining the construct (i.e. emotional confidence), they did not specify how it is formed rather they measured emotional confidence in a metacognitive way (certainty in emotional responses). According to Barbalet (2001) low spirit emotions such as anxiety, grief, dejection and despair are commonly associated with inactivity. Confidence in contrast to low spirit emotion, is an emotion without which action cannot take place; anxiety and other related emotions curtail inclination to act because they lead to uncertainty, whereas confidence based on feelings of certainty leads to action. According to Stajkovic (2006) confidence is certainty about something and it is a very important factor that enables us to act.

In this paper, emotional confidence is defined as affective certainty based strong positive emotions (Rizvi and Oney 2018). Emotional confidence is a consequence of feelings towards an object over period of time. Briñol et al (2007) concluded that emotions can influence confidence. In order to assess the influence of a specific emotional response on the emotional confidence, it is important to understand the underlying structure of the emotional response. According to 
Russell (1980) both valence and arousal are essential dimensions of an emotion. Both these dimensions of emotion have been widely recognized and it is important to note that arousal and intensity of an emotion is often used interchangeably (Anderson et al 2003; Izard 2007; Russell 1980; Russell and Carroll 1999; Smith and Ellsworth 1985).

Both valence and arousal are already embedded in an emotion for instance happiness and excitement are both positive valence emotions but with different levels of arousal. This idea stems from the circumplex model of emotions (Russell 1980). However, other academics argue that the intensity of an emotion reflects the combined effect of both valence and arousal (Strauss and Allen 2008; Reisenzein 1994)(Sonnemans and Frijda, 1994). Moreover, it is observed that the separate measure of emotional intensity reflects higher variance on its outcome variable (i.e. autobiographical memories) (Talarico et al 2004).

Emotional intensity can be defined as how a strong emotional experience combines the effect of both valence and arousal (Reisenzein 1994). In this study, intensity is used as an additional dimension in the formation of emotional confidence which reflects emotional experience including both valence and arousal. It is hypothesized that only valence of an emotional response will have positive influence on emotional confidence, it is further hypothesized that the combined effect of both valence (of emotion) and intensity will have higher influence on emotional confidence than only valence.

\section{Research method}

The data was collected from citizens of Swansea City UK using stratified random sampling. The strata were based on income level after identification of three areas higher, middle and lower levels. Random street numbers were generated for data collection. A survey questionnaire was used and the context was specified as the emotional response towards respondents' current car. Respondents were asked to specify the make and model of their cars.

The use of specific emotions related to the car were extracted from initial pilot focus groups and in-depth interviews. The extracted emotions were used to assess their emotional response on a scale ranging from 1 to 7 . In order to capture the valence of the emotion an initial scale of $-3,-2-10+1+2+3$ was used. Most of the respondents were in positive valence so the analysis conducted in this paper is only based on positive valence. To capture the intensity of each emotional response respondents were asked to specify the intensity from 1 (low intensity) to 7 (high intensity).

Rigorous pre-testing was applied to ensure readability, understanding and comprehension of all questions. Data was collected over a period of four months. In total, 675 subjects were approached and 222 agreed to participate; a response rate of approximately $32.8 \%$. The sample comprised 135 males $(60.8 \%)$, and 87 females $(39.2 \%)$ with a mean age of 47 . For purpose of grouping of emotional intensity, the respondents were recoded as low intensity groups and high intensity groups. Those who scored 6 and 7 were recoded as high intensity groups and rest were recoded as low intensity groups. For grouping of emotional confidence 


\section{W. Rizvi}

median split was used to categorize as low emotional confidence group and high emotional confidence group.

To assess relative influence of only valence and both valence and intensity models on emotional confidence structural equation modelling was used. To assess differences between low and high emotional intensity and emotional confidence in terms of purchase intentions independent $\mathrm{T}$ test was conducted. Further purchase intention (scale variable) was recoded as low and high purchase intentions using median split. After having three ordinal variables chi square was conducted between emotional confidence and purchase intentions and emotional intensity and purchase intensity respectively.

\subsection{Measures}

Six emotions were used in the study; unhappy-happy, bored-excited, annoyedpleased, disappointed-thrilled, regretful-content, unsatisfied-satisfied. The respondents were asked to specify the intensity of the emotion on a semantic differential scale of 1 to 7, 1 being low intensity and 7 being high intensity.

Emotional confidence was measured using the emotional confidence scale (ECS). The scale consists of 4 items, Likert scale 1 to 7 (Rizvi and Oney 2018). The measure of purchase intentions was adopted from a validated scale (see Jacoby and Chestnut, 1978) with six Likert items ranging from 1 to 7, 1 being strongly disagree and 7 being strongly agree.

\section{Hypotheses: Valence and intensity of an emotion}

Valence and intensity are considered to be the basic features of almost all emotional theories (Smith and Ellsworth (1985); Russell and Carroll (1999)). Kensinger (2004) concluded that both valence and intensity of an emotion influence memory and recall. Loewenstein \& Lerner (2003) also highlight the importance of emotional intensity, they state that low and moderate intensity emotions play an advisory role; as emotions intensify, they influence behaviour at an increasing pace. According to Clore (2000) emotional intensity can narrow attentional focus on the object, and narrow attention towards the object leads to more emotional intensity.

Hypotheses related to the influence of emotion on emotional confidence is divided in term of valence (direction of emotion) of each emotion and intensity as an additional dimension of the corresponding emotion. For example, if there is a positive influence of an emotion on confidence, it is further hypothesized that the addition of intensity of the same emotion as an additional measure, will increase the influence on emotional confidence and variance explained in emotional confidence will be higher as a result of the combined influence of valence and intensity compared to the influence of only valence of the emotion.

H1: Higher the happiness higher the emotional confidence

H1a: Combined (valence and intensity) influence of happiness on emotional confidence will be higher than the influence of only valence of happiness. 
H2: Higher the excitement higher the emotional confidence

H2a: Combined (valence and intensity) influence of excitement on emotional confidence will be higher than the influence of only valence of excitement.

H3: Higher the pleasure higher the emotional confidence

H3a: Combined (valence and intensity) influence of pleasure on emotional confidence will be higher than the influence of only valence of pleasure.

H4: Higher the thrill higher the emotional confidence

H4a: Combined (valence and intensity) influence of thrill on emotional confidence will be higher than the influence of only valence of thrill.

H5: Higher the contentment higher the emotional confidence

H5a: Combined (valence and intensity) influence of contentment on emotional confidence will be higher than the influence of only valence of contentment.

H6: Higher the satisfaction higher the emotional confidence

H6a: Combined (valence and intensity) influence of satisfaction on emotional confidence will be higher than the influence of only valence of satisfaction.

\section{Results}

The results were extracted using structural equation modeling (AMOS v 20). Before testing the structural model, the measurement model of emotional confidence was tested. The goodness of fit statistics indicate that, the proposed model fits the data well. The values of the indices are within the suggested thresholds representing the model fit. Table 1 shows factor loading, average variance extracted (AVE) and Cronbach Alpha.

The structural model in figure 1 shows the hypothesized, model only valence of an emotion and the combined effect of an emotion. The influence of emotion on the emotional confidence is presented in table 2. It shows beta coefficient, its statistical significance and variance explained by a model for both only valence effect and valence and intensity effect. Table 3 shows the model fit indices of the combined model (valence and intensity). The indices indicate that the data fits very well in the model. All indices are within suggested thresholds (Hair et al 2010).

The evidence observed in this study suggests that emotional response (positive valence) influences emotional confidence. It was further revealed that the intensity of the corresponding emotion enhances influence and the variance explained by the model. The result suggests that inclusion of intensity to the corresponding emotion enhances both the beta coefficient and the variance explained by the model and the result is consistent for all emotions (see table 2). This result is just an initial indication that the intensity of an emotion can be used as an additional dimension along with its valence.

Table 4 shows that the all hypotheses are affirmed. The result is consistent

Business Review: (2019) 14(1):68-80 


\section{W. Rizvi}

\begin{tabular}{lcc}
\multicolumn{3}{l}{ Table 1: Emotional confidence and purchase intentions measurement model } \\
\hline Emotional Confidence & Loadings & Reliability \& convergent validity \\
\hline$E C S_{1}$ & 0.86 & \\
$E C S_{2}$ & 0.76 & \\
$E C S_{3}$ & 0.95 & 0.70 \\
$E C S_{4}$ & 0.64 & 0.89 \\
Average variance Extracted & & \\
Cronbach Alpha & & \\
\hline Purchase Intentions & Loadings & Reliability \& convergent validity \\
\hline PI1 & 0.91 & \\
PI2 & 0.95 & \\
PI3 & 0.84 & \\
PI4 & 0.77 & \\
PI5 & 0.73 & 0.65 \\
PI6 & 0.63 & 0.91 \\
Average variance Extracted & & \\
Cronbach Alpha & & \\
\end{tabular}

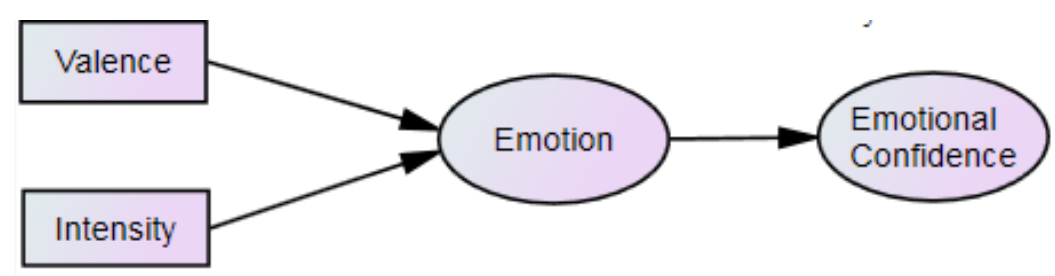

Only valence model

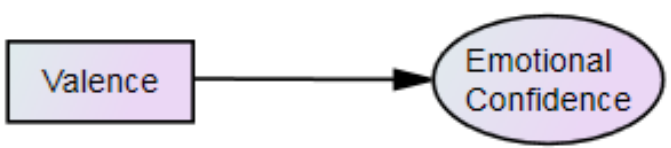

Fig. 1: Combined valence and intensity model

across all six emotions in terms of impact and variance explained in emotional confidence. When the intensity of an emotion was included in the model, the influence on emotional confidence was higher. Similarly, variance explained in emotional confidence was higher as well and the result was consistent across all six emotions. However, further research regarding this is required. If substantial evidence is accumulated that the inclusion of intensity in emotion measures attitudinal responses, then intensity can be studied as an additional dimension in attitude related models of buying behavior.

5.1 Grouping conditions: Level of separate emotional intensities and purchase intentions

It was further investigated whether or not there is statistically significant difference between low and high emotional intensity groups in relation to their 
Table 2: Beta coefficient, significance and variance explained

\begin{tabular}{lcccc}
\hline Emotion & Only valence & $\begin{array}{l}\text { Valence \& In- } \\
\text { tensity }\end{array}$ & $\begin{array}{l}\text { Variance explained } \\
\text { by only valence }\end{array}$ & $\begin{array}{l}\text { Variance explained } \\
\text { by valence \& inten- } \\
\text { sity }\end{array}$ \\
& $\beta$ and $\mathrm{P}$ value & $\beta$ and $\mathrm{P}$ value & & 0.12 \\
\hline Happy & $0.22(\mathrm{p}<0.05)$ & $0.35(\mathrm{p}<0.05)$ & 0.05 & 0.22 \\
Thrilled & $0.30(\mathrm{p}<0.05)$ & $0.47(\mathrm{p}<0.05)$ & 0.13 & 0.13 \\
Pleased & $0.31(\mathrm{p}<0.05)$ & $0.43(\mathrm{p}<0.05)$ & 0.1 & 0.18 \\
Excited & $0.32(\mathrm{p}<0.05)$ & $0.42(\mathrm{p}<0.05)$ & 0.11 & 0.29 \\
Content & $0.37(\mathrm{p}<0.05)$ & $0.53(\mathrm{p}<0.05)$ & 0.13 & 0.23 \\
Satisfied & $0.27(\mathrm{p}<0.05)$ & $0.48(\mathrm{p}<0.05)$ & 0.07 & \\
\hline
\end{tabular}

Table 3: Model fit indices: combined effect model (valence \& intensity)

\begin{tabular}{lccccc}
\hline Emotion & CMIN & CFI & GFI & RMSEA & SRMR \\
\hline Happy & 2.3 & 0.98 & 0.97 & 0.07 & 0.02 \\
Thrilled & 2.8 & 0.98 & 0.96 & 0.09 & 0.02 \\
Pleased & 2.6 & 0.98 & 0.96 & 0.08 & 0.03 \\
Excited & 3.7 & 0.97 & 0.95 & 0.11 & 0.05 \\
Content & 2.9 & 0.98 & 0.96 & 0.09 & 0.02 \\
Satisfied & 2.6 & 0.98 & 0.96 & 0.08 & 0.03 \\
\hline
\end{tabular}

Table 4: Hypotheses affirmation and impact on emotional confidence

\begin{tabular}{|c|c|c|c|}
\hline Hypothesis & $\begin{array}{l}\text { Hyp outcome } \\
(\mathrm{p}<.05)\end{array}$ & $\begin{array}{l}\text { Inf on Emotional conf } \\
\text { (comparing to other } \\
\text { model) }\end{array}$ & $\begin{array}{l}\text { Exp Var emotional conf } \\
\text { (comparing to other } \\
\text { model ) }\end{array}$ \\
\hline H1 only valence & Affirmed & Lower & Lower \\
\hline $\begin{array}{l}\text { H1a valence and intensity } \\
\text { Happiness } \rightarrow \text { Emotional confi- } \\
\text { dence }\end{array}$ & Affirmed & Higher & Higher \\
\hline $\mathrm{H} 2$ only valence & Affirmed & Lower & Lower \\
\hline $\begin{array}{l}\text { H2a Valence and intensity } \\
\text { Excitement } \rightarrow \text { Emotional con- } \\
\text { fidence }\end{array}$ & Affirmed & Higher & Higher \\
\hline H3 only valence & Affirmed & Lower & Lower \\
\hline $\begin{array}{l}\text { H3a Valence and intensity } \\
\text { Pleasure } \rightarrow \text { Emotional confi- } \\
\text { dence }\end{array}$ & Affirmed & Higher & Higher \\
\hline H4 only valence & Affirmed & Lower & Lower \\
\hline $\begin{array}{l}\text { H4a Valence and intensity } \\
\text { Thrill } \rightarrow \text { Emotional confi- } \\
\text { dence }\end{array}$ & Affirmed & Higher & Higher \\
\hline H5 only valence & Affirmed & Lower & Lower \\
\hline $\begin{array}{l}\text { H5a Valence and intensity } \\
\text { Contentment } \rightarrow \text { Emotional } \\
\text { confidence }\end{array}$ & Affirmed & Higher & Higher \\
\hline $\begin{array}{l}\text { H6 only valence } \\
\text { H6a Valence and intensity } \\
\text { Satisfaction } \rightarrow \text { Emotional con- } \\
\text { fidence }\end{array}$ & $\begin{array}{l}\text { Affirmed } \\
\text { Affirmed }\end{array}$ & $\begin{array}{l}\text { Lower } \\
\text { Higher }\end{array}$ & $\begin{array}{l}\text { Lower } \\
\text { Higher }\end{array}$ \\
\hline
\end{tabular}

Business Review: (2019) 14(1):68-80 
purchase intentions. Table 5 shows results of the independent $t$ test across dif-

Table 5: Independent sample $\mathrm{T}$ test across different emotional intensities

\begin{tabular}{lcc}
\hline Emotional Intensity & Purchase Intentions Mean & Significance level \\
\hline Happy Intensity & Low 25.31-High 32.90 & $\mathrm{P}<0.001$ \\
Thrill Intensity & Low 26.19-High 32.14 & $\mathrm{P}<0.001$ \\
Pleased Intensity & Low 25.90-High 31.85 & $\mathrm{P}<0.001$ \\
Excited Intensity & Low 26.93-High 32.12 & $\mathrm{P}<0.001$ \\
Content Intensity & Low 25.86-High 31.70 & $\mathrm{P}<0.001$ \\
Satisfied Intensity & Low 25.34-High 31.93 & $\mathrm{P}<0.001$ \\
\hline
\end{tabular}

ferent emotions with two levels, low intensity and high intensity.

Results suggest that there is statistically significant difference between low and high intensity groups in terms of purchase intentions across all observed emotions. In all tests groups with low emotional intensity demonstrated low purchase intentions and vice versa. Similarly, independent $t$ tests were conducted on two other grouping variables and the responses were grouped in terms of overall emotional intensity and emotional confidence.

Table 6 shows that there was statistically significant difference between over-

Table 6: Independent sample $\mathrm{T}$ test across different emotional intensities

\begin{tabular}{lcc}
\hline Grouping variable & Purchase intentions mean & Significance level \\
\hline Emotional intensity & Low 26.53-High 32.90 & $\mathrm{P}<0.001$ \\
Emotional confidence & Low 26.98-High 32.13 & $\mathrm{P}<0.001$ \\
\hline
\end{tabular}

all low emotional intensity and overall high emotional intensity in terms of their purchase intentions. Similarly, there was statistically significant difference between low emotional confidence and high emotional confidence groups in terms of purchase intention.

Further purchase intention variable was broken down to a groping variable based on median split. Relationship between overall emotional intensity, emotional confidence and purchase intention was assessed. Each variable had two levels (Low-High). Table 7 shows the result of chi square and Phi Cramer's V suggest that there is statistically significant association between overall intensity and purchase intention and the strength of the relationship is moderate.

Table 7: Chi square overall intensity and purchase intentions

\begin{tabular}{lcc}
\hline Grouping relationship & Chi square & Phi-Cramer's V \\
\hline Overall intensity and purchase intent & $21.57 \mathrm{P}<0.001$ & $0.323 \mathrm{P}<0.001$ \\
\hline
\end{tabular}

Figure 2 shows that the groups with low emotional intensity demonstrated low purchase intentions (higher count) compared to high purchase intention. 


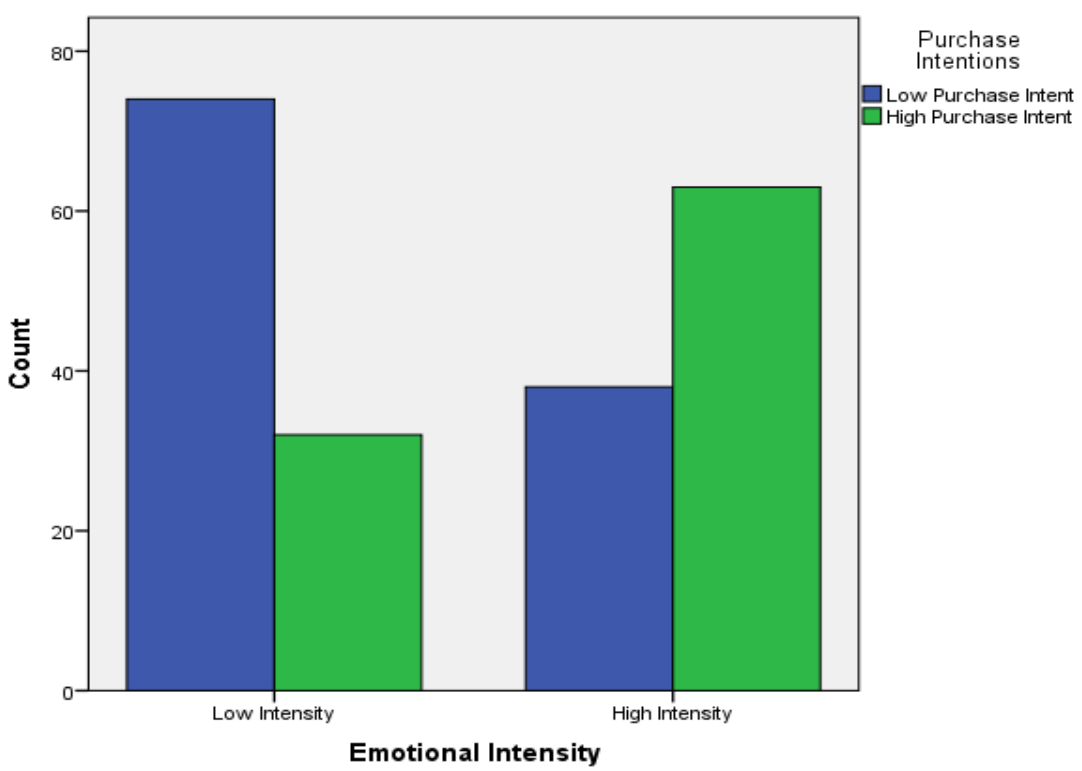

Fig. 2: Level of emotional intensity and purchase intentions

Table 8: Chi square emotional confidence and purchase intentions

\begin{tabular}{lcc}
\hline Grouping Relationship & Chi square & Phi-Cramer's V \\
\hline Emotional Confidence and Purchase Intent & $17.28 \mathrm{P}<0.001$ & $0.289 \mathrm{P}<0.001$ \\
\hline
\end{tabular}

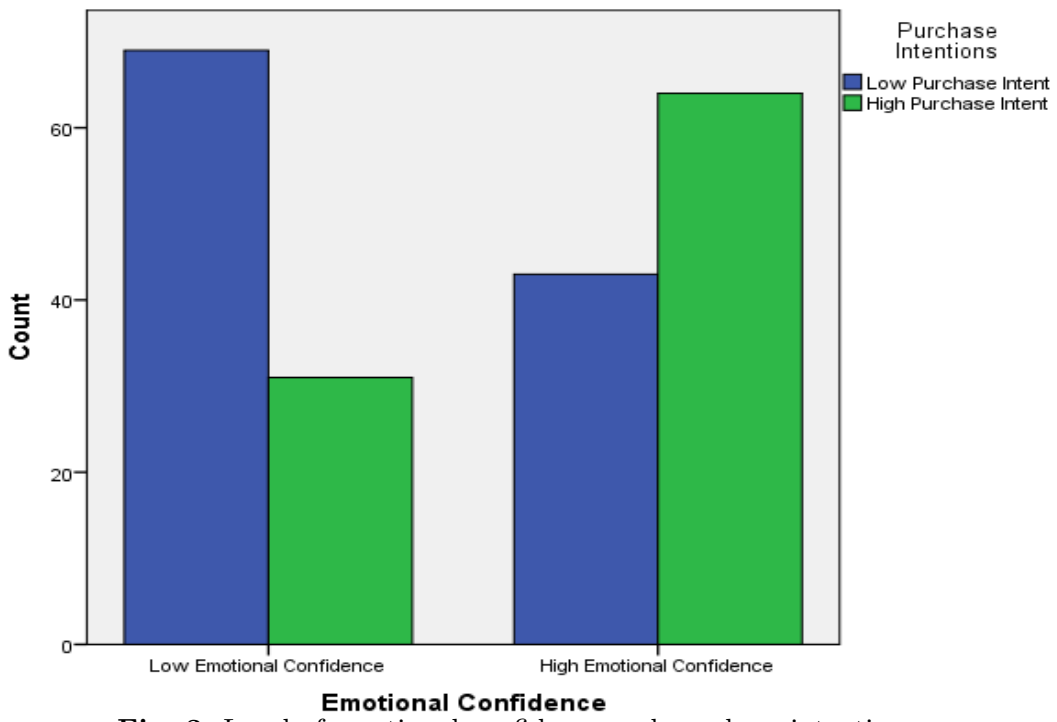

Fig. 3: Level of emotional confidence and purchase intentions

Similarly, high emotional intensity groups demonstrated high purchase intentions (higher count) compared to low purchase intentions. Table 8 shows the result of chi square and Phi Cramer's V suggest that there is statistically sig-

Business Review: (2019) 14(1):68-80 


\section{W. Rizvi}

nificant association between overall intensity and purchase intention and the strength of the relationship is low. Figure 3 shows that the groups with low emotional confidence demonstrated low purchase intentions (higher count) compared to high purchase intention. Similarly, high emotional confidence groups demonstrated high purchase intentions (higher count) compared to low purchase intentions.

\section{Conclusion and managerial implications}

Confidence is conceived as a cognitive construct. Conceptualization and measurement of emotion based confidence is an emerging phenomenon. Both valence (direction) and intensity (strength) of an emotion are essential to form emotional confidence towards an object. The focus of this paper was, to determine the influence of both valence and intensity of an emotion. The results suggest that valence has a positive influence on emotional confidence. It was further revealed that including the intensity of each corresponding emotion as an additional measure increases influence on both emotional confidence and variance explained in emotional confidence. This paper provides empirical evidence that the intensity of an emotion is a determinant of the emotional confidence. The results related to all emotions were consistent, both influence and variance explained increased after adding the intensity of the emotion in the model.

The results related to each emotional intensity as grouping condition (low intensity and high intensity) suggest that there is statistically significant difference between low and high intensity respondents in terms of purchase intentions. Higher the intensity, higher the purchase intentions and the results were consistent across each emotion. Moreover, there was statistically significant difference between low emotional confidence and higher emotional confidence in terms of their purchase intentions, higher the emotional confidence, higher the purchase intentions.

This study highlights implications for both academic and practitioners, using emotional intensity as an additional dimension with respect to valence of an emotional response towards an object, indicates the number of possibilities in which we can use existing buying behavior frameworks. For instance, measure of emotional intensity along with emotional response towards a brand would provide additional insights. Similarly, the additional measure is essential as it can help marketing managers to look into consumers' experience that elicit strong (high intense) emotions that may presumably form affective certainty (i.e. emotional confidence) towards a brand. Intensity (as an additional measure) of an emotion can be employed to assess other constructs like attitude towards a brand, intensity of an attitude can be used as a moderating variable. Apart from the emotional confidence research stream, influence of emotions on brands is widely tested, intensity of an emotion can be used as complimentary dimension (as results sought in this study) to assess its impact on a brand or product. 


\subsection{Limitations of the study}

Presumably higher emotional intensity in the direction of the valence would have certain influence and that influence should be consistent with the observed valence. For instance, if respondents experience positive (valence direction) emotions with certain degree of intensity, it will have positive influence on purchase intentions. When respondents experience negative (valence direction) emotions with a certain degree of intensity, it will have negative influence on purchase intentions. This paper only deals with positive emotions as there were no sizeable responses (study limitation) related to negative emotions. This could be affirmed in future studies specially with brands or products that have negative emotional association.

\section{References}

Ajzen I (2005) Attitudes, personality, and behavior. McGraw-Hill Education (UK)

Anderson AK, Christoff K, Stappen I, Panitz D, Ghahremani D, Glover G, Gabrieli JD, Sobel N (2003) Dissociated neural representations of intensity and valence in human olfaction. Nature neuroscience 6(2):196

Bandura A (1977) Self-efficacy: toward a unifying theory of behavioral change. Psychological review $84(2): 191$

Bearden WO, Hardesty DM, Rose RL (2001) Consumer self-confidence: Refinements in conceptualization and measurement. Journal of consumer research 28(1):121-134

Berger IE (1992) The nature of attitude accessibility and attitude confidence: A triangulated experiment. Journal of Consumer Psychology 1(2):103-123

Berger IE, Mitchell AA (1989) The effect of advertising on attitude accessibility, attitude confidence, and the attitude-behavior relationship. Journal of consumer research 16(3):269-279

Briñol P, Petty RE, Barden J (2007) Happiness versus sadness as a determinant of thought confidence in persuasion: A self-validation analysis. Journal of Personality and Social psychology 93(5):711

Compte O, Postlewaite A (2004) Confidence-enhanced performance. American Economic Review 94(5):1536-1557

Curtin RT (1982) Indicators of consumer behavior: The university of michigan surveys of consumers. Public Opinion Quarterly 46(3):340-352

Dees S, Brinca PS (2013) Consumer confidence as a predictor of consumption spending: Evidence for the united states and the euro area. International Economics 134:1-14

Dominitz J, Manski CF (2004) How should we measure consumer confidence? Journal of Economic Perspectives 18(2):51-66

Gross K, Brewer PR, Aday S (2009) Confidence in government and emotional responses to terrorism after september 11, 2001. American Politics Research 37(1):107-128

Hair JF, Anderson RE, Babin BJ, Black WC (2010) Multivariate data analysis: A global perspective (vol. 7)

Howard JA, Sheth JN (1969) The theory of buyer behavior. New York p 63

Izard CE (2007) Basic emotions, natural kinds, emotion schemas, and a new paradigm. Perspectives on psychological science 2(3):260-280

Kahneman D, Lovallo D (1993) Timid choices and bold forecasts: A cognitive perspective on risk taking. Management science 39(1):17-31

Kidwell B, Hardesty DM, Childers TL (2008) Emotional calibration effects on consumer choice. Journal of Consumer Research 35(4):611-621

Krosnick JA, Boninger DS, Chuang YC, Berent MK, Carnot CG (1993) Attitude strength: One construct or many related constructs? Journal of personality and social psychology $65(6): 1132$

Laroche M, Kim C, Zhou L (1996) Brand familiarity and confidence as determinants of purchase intention: An empirical test in a multiple brand context. Journal of business Research $37(2): 115-120$

Business Review: (2019) 14(1):68-80 


\section{W. Rizvi}

Ludvigson SC (2004) Consumer confidence and consumer spending. Journal of Economic perspectives 18(2):29-50

Petty RE, Briñol P, Tormala ZL (2002) Thought confidence as a determinant of persuasion: the self-validation hypothesis. Journal of personality and social psychology 82(5):722

Reisenzein R (1994) Pleasure-arousal theory and the intensity of emotions. Journal of Personality and Social Psychology 67(3):525

Rizvi WH, Oney E (2018) The influence of emotional confidence on brand attitude: using brand belief as mediating variable. Economic research-Ekonomska istraživanja 31(1):158 170

Russell JA (1980) A circumplex model of affect. Journal of personality and social psychology 39(6): 1161

Russell JA, Carroll JM (1999) On the bipolarity of positive and negative affect. Psychological bulletin 125(1):3

Siegrist M, Gutscher H, Earle TC (2005) Perception of risk: the influence of general trust, and general confidence. Journal of risk research 8(2):145-156

Smith CA, Ellsworth PC (1985) Patterns of cognitive appraisal in emotion. Journal of personality and social psychology 48(4):813

Smith RE, Swinyard WR (1988) Cognitive response to advertising and trial: Belief strength, belief confidence and product curiosity. Journal of Advertising 17(3):3-14

Sniezek JA, Paese PW, Switzer III FS (1990) The effect of choosing on confidence in choice. Organizational Behavior and Human Decision Processes 46(2):264-282

Stajkovic AD (2006) Development of a core confidence-higher order construct. Journal of Applied Psychology 91(6):1208

Strauss GP, Allen DN (2008) Emotional intensity and categorisation ratings for emotional and nonemotional words. Cognition and emotion 22(1):114-133

Talarico JM, LaBar KS, Rubin DC (2004) Emotional intensity predicts autobiographical memory experience. Memory \& cognition 32(7):1118-1132 